\title{
Developing a Virtual Counter for Radiation Detection Systems
}

\author{
Gözde TEKTAŞ ${ }^{1,2 *}$, Cüneyt ÇELIKTAŞ² \\ *Correspond Author: gozdetektas@hotmail.com \\ ${ }^{1}$ Izmir University of Economics, Faculty of Arts and Sciences, Department of Physics, IZMIR \\ Orcid No: 0000-0003-3360-5236/gozdetektas@hotmail.com \\ ${ }^{2}$ Ege University, Faculty of Science, Physics Department, IZMIR \\ Orcid No: 0000-0001-8608-066X / cceliktas@yahoo.com
}

\begin{abstract}
A virtual counter was developed to count the signals from a scintillation detector. After the signals were processed by some electronic devices, they were counted by the virtual counter and a real counter. The counts obtained from both counters were accumulated via different amplifier gains and source-to-detector distances to investigate their effects on the recorded counts. The results from the virtual counter were compared with those of the real one. It was concluded that the developed virtual counter could be used to count the radiation detector signals like a real counter.
\end{abstract}

Keywords: Virtual counter, Real counter, Scintillation detector signal

\section{Radyasyon Dedeksiyon Sistemleri için Bir Sanal Sayıcı Geliştirilmesi}

Öz: $\mathrm{Bu}$ çalışmada, sintilasyon dedektöründen gelen sinyalleri saymak için bir sanal sayıcı geliştirilmiştir. Sinyaller bazı elektronik cihazlar tarafından işlendikten sonra sanal ve gerçek sayıcılar tarafından sayılmıştır. Farklı yükseltici kazançları ve kaynak dedektör mesafeleri için her iki sayıcıdan sayımlar alınmıştır. Sanal sayıııdan alınan sonuçlar gerçek sayıcıdan alınan sonuçlarla karşılaştırılmışıı. Geliştirilen sanal sayıcının gerçek bir sayıcı gibi radyasyon dedektör sinyallerini saymak için kullanılabileceği sonucuna varılmıştır.

Anahtar Kelimeler: Sanal sayıcı, Gerçek sayııı, Sintilasyon dedektör sinyali

\section{Introduction}

A counter is a device that counts the signals from a signal source within a fixed time. The difference between a virtual counter and a real counter is that the virtual counter is developed via software in a computer environment although the real one is a device produced by the manufactory.

The virtual counter can be developed using LabVIEW software functions. LabVIEW is a graphical programming environment. For measurement and automation, it is a powerful and versatile analysis and instrumentation software system (Jerome, 2010). Since its programming language is based on a graphical representation, the developer feels free from the usual sequential architecture of a text-based programming language (Tooley, 2005).

One of the most often and widely used particle detection devices in nuclear and particle physics is a scintillation detector (Leo, 1987). A gamma ray interacting with a 
scintillator produces a pulse of light that is converted to an electric pulse by the scintillation detector (ORTEC, 2021). Thallium activated sodium iodide $(\mathrm{NaI}(\mathrm{Tl}))$ is the most commonly used scintillator for gamma ray detection (Tsoulfanidis, 1995).

A virtual instrument was designed to count output pulses from Geiger Müller counter by using PFI pin of DAQ card by Quraishi and Hoque (Quraishi and Hoque, 2010-2011). Jie et al. designed a virtual instrument that Ortec model 974 counter/timer was controlled, and the counts acquired from the model 974 were displayed. Communication between PC and the model 974 was provided via PCI-GPIB card (Jie et al., 2009). Tektas and Celiktas developed a virtual counter for the pulses from a function generator. The signals from the function generator were counted by the virtual counter and a real counter. Analog input and PFI line of a DAQ device were used in the study (Tektas and Celiktas, 2017). Kapri et al. developed a LabVIEWbased photon counting program for continuous data acquisition using SR400 gated photon counter and statistical analysis (Kapri et al., 2020).
In this work, the signals from the scintillation detector were counted by the virtual counter through a digitizer and the real counter. The counts were accumulated by both counters according to change of the amplifier gains and the source-to-detector distances to test the performance of the virtual counter. The counts from both counters were compared with each other.

\section{Materials and Methods}

In this study, a virtual counter was designed by developing a code via LabVIEW software for counting the signals. In the front panel of the virtual counter, a screen and an indicator display the signals and the number of counts. The signals were acquired through a digitizer (NI 5133). NISCOPE functions which are the driver functions of the digitizer were used to accept the signals. The virtual counter runs and counts the accepted signals in a fixed acquisition time. A section from the front panel and block diagram of the virtual counter are given in Figure 1. 


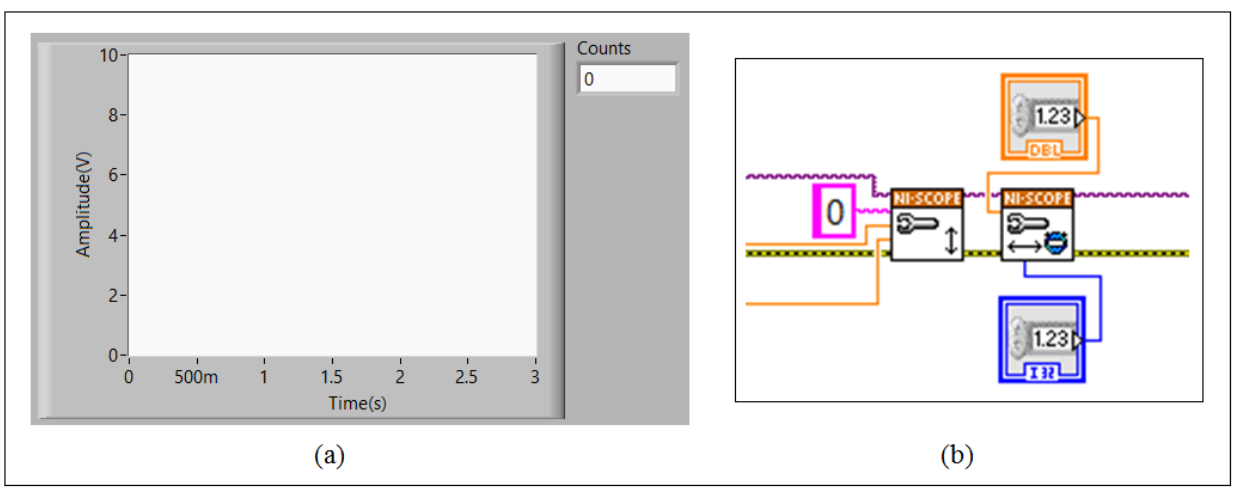

Figure 1. (a) Front panel and (b) block diagram of the virtual counter.

${ }^{137} \mathrm{Cs}$ radiation source with the preamplifier is necessary (Tsoulfanidis, activity of $5 \mu \mathrm{Ci}$ was used in this 1995). An amplifier increases the voltage experiment. The signals from a $\mathrm{NaI}(\mathrm{Tl})$ (3 amplitude of each pulse by a predetermined inch by 3 inch) scintillation detector were processed by a preamplifier (ORTEC 113) gain factor, and provides some pulse shaping (ORTEC, 2021). The signals from and an amplifier (ORTEC 485), respectively. A preamplifier provides an optimized coupling between the output of the detector and the rest of the counting system. Besides, to minimize any sources of noise that may change the signal the the amplifier were counted by the virtual counter and a real counter (ORTEC 775). Data acquisition time of the real counter was set using a timer (ORTEC 719). A circuit schema used for the measurements is shown in Figure 2.

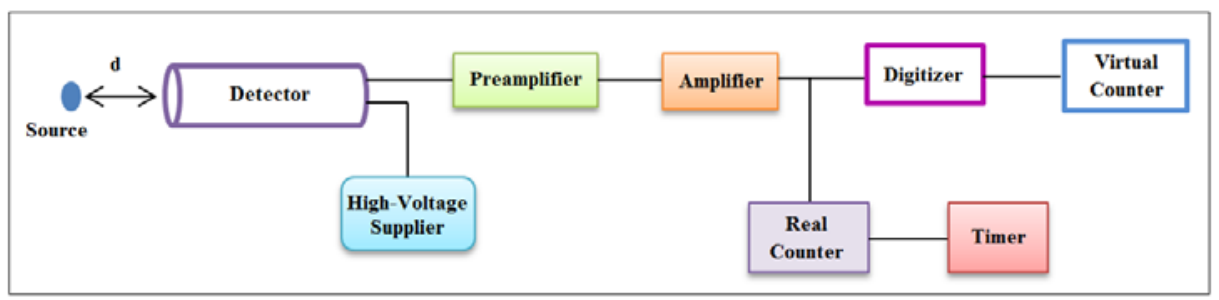

Figure 2. A block diagram for the measurements (d: source-to-detector distance).

For comparing the number of counts obtained from both counters according to the frequency change, the source-to-detector distance was set to $1,2,3$ and $4 \mathrm{~cm}$, respectively. The acquisition time was set to 100, 200 and $400 \mathrm{~s}$ to compare the obtained counts at different times. The coarse and fine gain values were kept constant to 32 and 10 respectively during all measurements.

The coarse gain value of the amplifier was also changed to investigate whether the counts from both counters were compatible with each other. So, it was adjusted to $2,4,8$, 16 and 32, respectively. The fine gain was set 
to its minimum value during all measurements. The acquisition time was kept constant to $100 \mathrm{~s}$.

Each count was repeated three times by both counters, and the averages of the counts were determined and compared with each other. The results from the virtual counter are given in the next section.

\section{Results and Conclusion}

The counts were obtained from both counters for the different source-to-detector distances (d) and for the acquisition times of 100,200 and $400 \mathrm{~s}$. The results are given in Tables 1-3. The results given in the Tables are also presented graphically in Figures 3-5.

Table 1. Average counts obtained from both counters in $100 \mathrm{~s}$.

\begin{tabular}{|c|c|c|}
\hline $\mathbf{d}(\mathbf{c m})$ & $\begin{array}{c}\text { Real Counter } \\
\text { Average Counts }\end{array}$ & $\begin{array}{c}\text { Virtual Counter } \\
\text { Average Counts }\end{array}$ \\
\hline $\mathbf{1}$ & $1313432 \pm 662$ & $1317209 \pm 663$ \\
\hline $\mathbf{2}$ & $1027968 \pm 585$ & $1051091 \pm 592$ \\
\hline $\mathbf{3}$ & $829571 \pm 526$ & $837860 \pm 528$ \\
\hline $\mathbf{4}$ & $689344 \pm 479$ & $697803 \pm 482$ \\
\hline
\end{tabular}

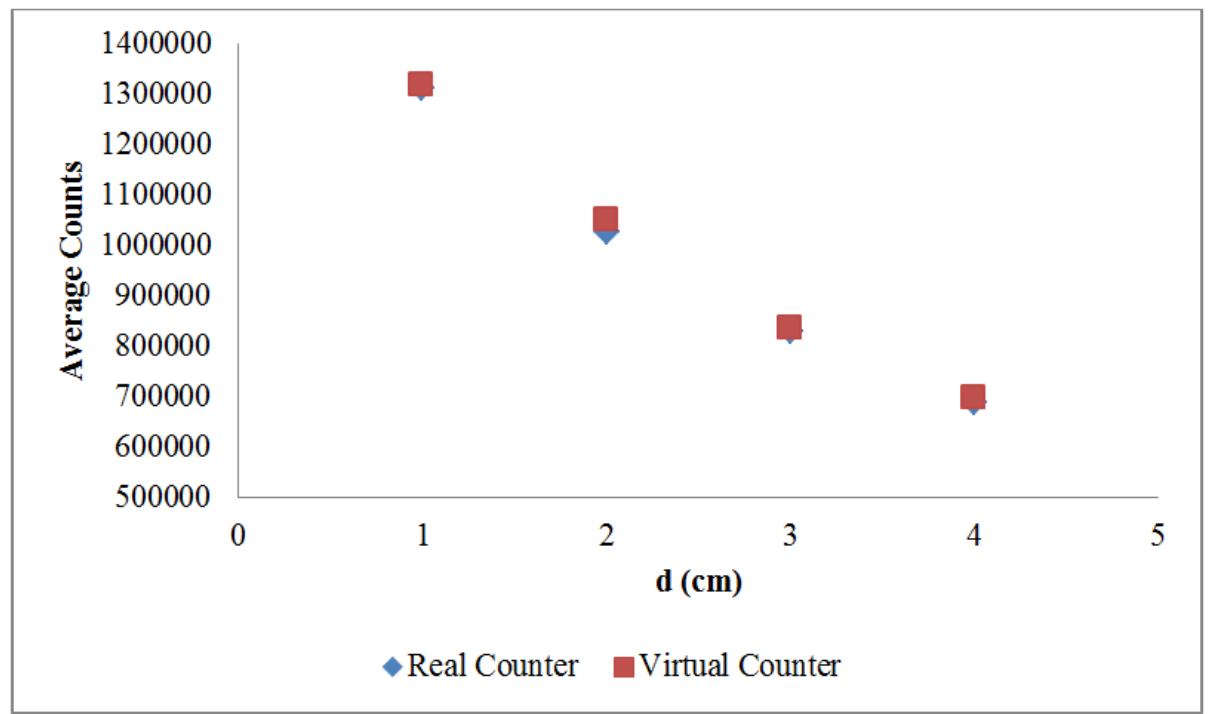

Figure 3. Average counts versus distance change in $100 \mathrm{~s}$.

Table 2. Average counts obtained from both counters in $200 \mathrm{~s}$.

\begin{tabular}{|c|c|c|}
\hline $\mathbf{d}(\mathbf{c m})$ & $\begin{array}{c}\text { Real Counter } \\
\text { Average Counts }\end{array}$ & $\begin{array}{c}\text { Virtual Counter } \\
\text { Average Counts }\end{array}$ \\
\hline $\mathbf{1}$ & $2625726 \pm 936$ & $2626948 \pm 936$ \\
\hline $\mathbf{2}$ & $2054048 \pm 827$ & $2094323 \pm 836$ \\
\hline $\mathbf{3}$ & $1657044 \pm 743$ & $1664452 \pm 745$ \\
\hline $\mathbf{4}$ & $1379270 \pm 678$ & $1397529 \pm 683$ \\
\hline
\end{tabular}




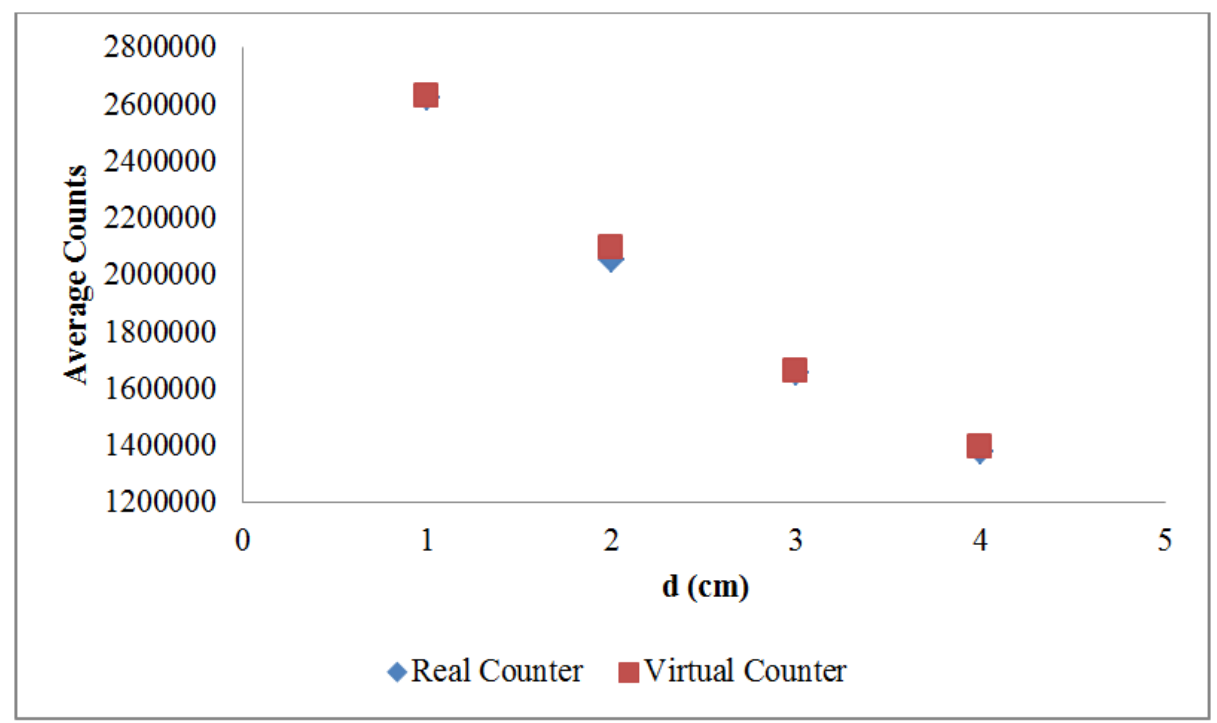

Figure 4. Average counts versus distance change in $200 \mathrm{~s}$.

Table 3. Average counts obtained from both counters in $400 \mathrm{~s}$.

\begin{tabular}{|c|c|c|}
\hline $\mathbf{d}(\mathbf{c m})$ & $\begin{array}{c}\text { Real Counter } \\
\text { Average Counts }\end{array}$ & $\begin{array}{c}\text { Virtual Counter } \\
\text { Average Counts }\end{array}$ \\
\hline $\mathbf{1}$ & $5252388 \pm 1323$ & $5302141 \pm 1329$ \\
\hline $\mathbf{2}$ & $4110840 \pm 1171$ & $4179303 \pm 1180$ \\
\hline $\mathbf{3}$ & $3320132 \pm 1052$ & $3334132 \pm 1054$ \\
\hline $\mathbf{4}$ & $2787783 \pm 964$ & $2951947 \pm 992$ \\
\hline
\end{tabular}

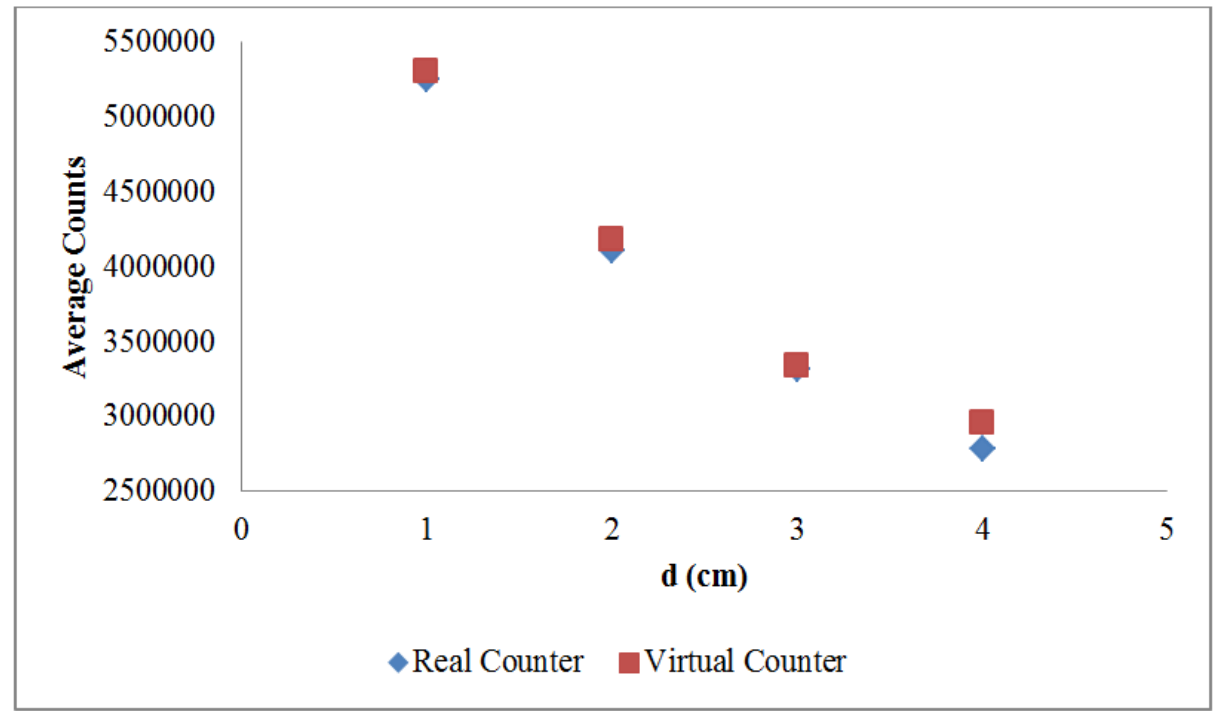

Figure 5. Average counts versus distance change in $400 \mathrm{~s}$.

For the different amplifier gain values, the average counts obtained from the real counter and the virtual counter are shown in Table 4. They are also given graphically in Figure 6. It was aimed at testing whether the counts from the virtual counter were compatible with those of the real one considering change of the coarse gain value with the constant acquisition time. 
Table 4. Average counts obtained from both counters in $100 \mathrm{~s}$ for different gain values.

\begin{tabular}{|c|c|c|}
\hline Coarse Gain & $\begin{array}{c}\text { Real Counter } \\
\text { Average Counts }\end{array}$ & $\begin{array}{c}\text { Virtual Counter } \\
\text { Average Counts }\end{array}$ \\
\hline $\mathbf{2}$ & $549231 \pm 428$ & $556029 \pm 431$ \\
\hline $\mathbf{4}$ & $786438 \pm 512$ & $795379 \pm 515$ \\
\hline $\mathbf{8}$ & $992671 \pm 575$ & $1004593 \pm 579$ \\
\hline $\mathbf{1 6}$ & $1033273 \pm 587$ & $1045839 \pm 590$ \\
\hline $\mathbf{3 2}$ & $1060077 \pm 594$ & $1080111 \pm 600$ \\
\hline
\end{tabular}

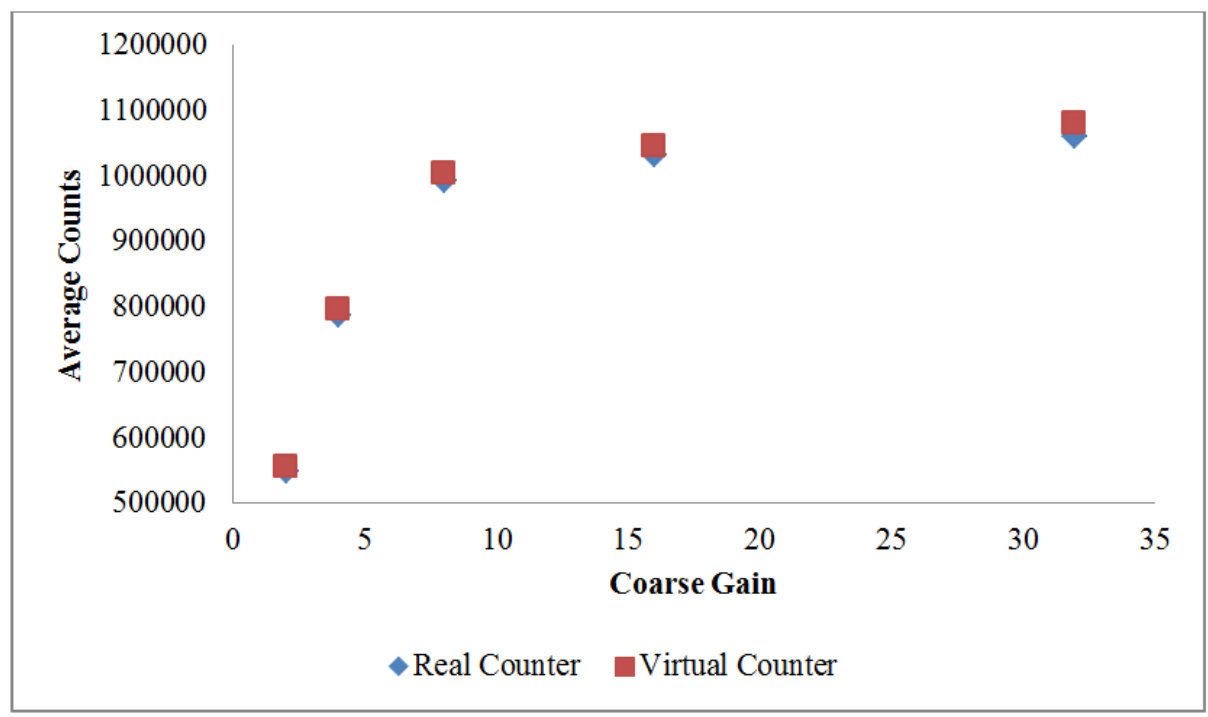

Figure 6. Average counts versus coarse gain change in $100 \mathrm{~s}$.

As can be seen in the Tables and Figures 3-6, the counts acquired from the virtual counter were highly compatible with those of the real one. As the sourceto-detector distance was increased, the signal frequency i.e. the incident particles that enter in the detector were decreased. Because of this, the counts were reduced. For the same source-to-detector distance, it was seen from these tables that the counts were increased when the acquisition time was increased as expected. If the gain values of the amplifier were increased, the amplitude values of the signals were normally increased. So, the counts obtained from both counters were increased as seen in Table 4.

In the presented study, to determine the counts of the incident particles that enter in the detector, a virtual counter was designed via software that it would be able to substitute of the real one. For this, a real counter was used to test the performance of the developed virtual counter. A gamma detection spectrometer given in Figure 2 was used for this purpose. The average counts obtained from the virtual and real counters for different source-to-detector distances and amplifier gain values were compared. 
A virtual counter was developed via a written code that runs under LabVIEW program. This kind of work can be named as virtual instrumentation. It can be briefly expressed as the production of an electronic device in the computer environment through a software. In this manner, the user can add the options to his/her designed device, leading to ease of use. The counting and the graphical display of the signals in the same screen, in this respect, was possible in the front panel of the virtual counter as an its advantage compared to the real one.

The authors have developed a virtual counter for the signals from a generator before by using NI USB-6008 multifunction data acquisition device through its analog input and PFI line for the data input to the computer (Tektas and Celiktas, 2017). Unlike that work, a real radiation detector signals instead of a generator, a digitizer (NI 5133), NISCOPE functions and the digital input were used here for the signal acquisition; and the results were highly satisfactory.

Finally, it was concluded from the work that the developed virtual counter with different data acquisition method through the designed code under LabVIEW here could be used to count the detector signals like its real in nuclear physics experiments.

\section{Acknowledgement}

This work was supported by Scientific Research Foundation of Ege University under project No. 14 FEN 052.

\section{References}

Jerome J (2010). Virtual Instrumentation Using LabVIEW, PHI Learning Private Limited. New Delhi.

Jie Y, Rong L, Cheng L, Li J, Xinxin L, Tonghua Z, Mei W, Zhongwei W, Jufang L (2009). LabVIEW-based auto-timing counts virtual instrument system with ORTEC 974 Counter/Timer. Nuclear Science and Techniques 20: 307-311.

Kapri RK, Rathore K, Dubey PK, Mehrotra R, Sharma P (2020). Optimization of control parameters of PMT-based photon counting system. MAPAN 35(2): 177-182.

Leo WR (1987). Techniques for nuclear and particle physics experiments. Springer-Verlag, Berlin.

ORTEC. 905 Series NaI(Tl) Scintillation Detectors. https://www.ortec-online.com/$/ \mathrm{media} /$ ametekortec/brochures/905-a4.pdf?dmc $=1 \& l \mathrm{a}=$ en\&revision $=41363 \mathrm{~b} 5 \mathrm{~b}-3 \mathrm{e} 7 \mathrm{~d}$ 44b7-aa92-ab2fa8f53691 (Accessed: 02/03/2021)

ORTEC. Experiment IV-1 Introduction to electronic signal analysis in nuclear radiation measurements. https://www.ortec-online.com/-/media/ametekortec/fourth-edition- 
experiments/fourth-ed-1.pdf?dmc=1\&la=en\&revision=e3d1952c-9aa6-4688-b91a09292ea34567\&hash=008EFCFEEF08811C17FD9B48E583C507

(Accessed: $02 / 03 / 2021)$

Quraishi MH, Hoque Md. A (2010-2011). Computer based radioactivity measurement with acquisition and monitoring radiation data using LabVIEW. Electrical and Electronic Engineering Department of Bangladesh University of Engineering and Technology, Bangladesh.

Tektas G, Celiktas C (2017). Comparison of a designed virtual counter with a real counter. AIP Conf Proc 1815: 060022-1 - 060022-4.

Tooley M (2005). PC based instrumentation and control, Third Edition, Elsevier, Burlington.

Tsoulfanidis N (1995). Measurement and detection of radiation, Second Edition, Taylor \& Francis, London. 